\title{
Mumps Virus IgG Antibody Measurement
}

National Cancer Institute

\section{Source}

National Cancer Institute. Mumps Virus Ig G Antibody Measurement. NCI Thesaurus.

Code C122136.

The determination of the amount of mumps virus IgG antibody present in a sample. 